\title{
The Importance of Knowledge of Provenance for the Provenance of Knowledge: The Case of Traditional Costumes Collections in Greece
}

\author{
Eleni Papathoma
}

Curator at Museum of Modern Greek Culture, Thespidos 8, GR-105 58 Athens, Greece; papathoma@gmail.com

Received: 31 January 2019; Accepted: 15 February 2019; Published: 19 February 2019

\begin{abstract}
In Greece there are several collections of "traditional costumes", i.e., garments with a strongly local character, which were in use up to the early 20th century. "Traditional costumes" are directly linked to Modern Greek folk culture: they were formed in its context and they are its most typical and obvious image. They have often been used as a national icon and are popular with people of all ages, who admire them and, on occasions of national celebrations and dance festivals, take pleasure and pride in dressing in replicas of them. Since they have stopped being worn many decades ago, the existing collections are a major source for their study, and they are respectfully referred to by scholars, the public and makers of replicas. The provenance of these collections-the criteria used, the persons involved, the purposes served, etc.-deeply affects the extent and the nature of our knowledge on the objects included in them. Given the inadequate information usually recorded on provenance issues, a thorough search of all potential sources with an aim to put together 'biographies' of collections will help to understand the collecting context of the objects and their respective historical and interpretational value.
\end{abstract}

Keywords: provenance; collections; dress history

\section{Introduction: Greek Traditional Costumes: Historical Evidence, Living Heritage, Identity Symbols}

I have been the curator of the costumes collection at the Museum of Modern Greek Culture since 2012. One day I received a phone call from a woman who represented a folk-dance group from a Greek town. She asked for permission to photograph the women's costume of the nomads of Pindos which was on display at the Museum (Figure 1), in order to have replicas made for use in her group's performances; no other dance group in their region used such a costume, she said, so it would help theirs stand out. She then asked why the mannequin wearing it at the exhibition had blonde hair: did this mean that the women who used to dress like this were mostly blonde? Because, she said, if that was the case, they would have blonde wigs made to wear themselves when dancing dressed in this costume.

This incident shows quite vividly that people look to museums as reliable sources of the "authentic" knowledge of things. But to what extent do the museums actually possess the "authentic" knowledge demanded? Although a museum may admit to not knowing the hair color of the original wearers of a costume, is it, at least, certain that the costume in question is adequately documented in order to be presented as historical evidence and used as such?

The limits of this kind of certainty are the core of this paper's discussion [1]. 


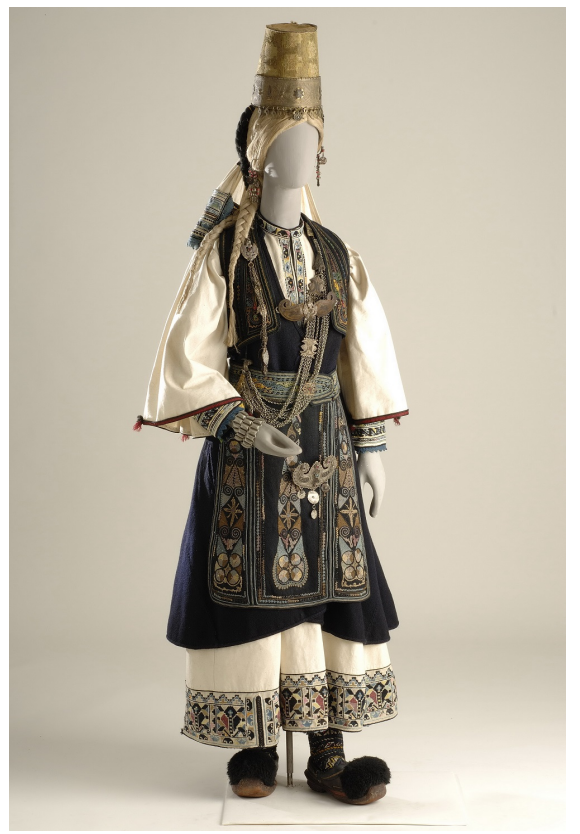

Figure 1. Traditional costume of the Pindos nomads. Museum of Modern Greek Culture, Reg. No. 3448.

Although in the Greek bibliography there are several publications regarding "traditional" dress, little has been written yet on the ways it has been collected, preserved and presented and even less on how these processes have affected our knowledge of it. Besides scarce approaches to individual collections [2] or specific subjects [3], there has been a courageous attempt by the Hellenic Costume Society to map "the existing dress collection landscape" in a survey analyzed and presented by Xenia Politou at the "Endyesthai" Conference in 2010 [4]. At around the same time, in 2011, Marina Vrelli-Zachou and Nadia Macha-Bizoumi, in their essay on the local dress of the Thassos island [5], took a crucial step forward, not only showing how the existing museum collections are a valuable source for the study of historical dress but also stressing the importance of surveying museum records when using museum objects as a source. Carrying this argument a bit further, my paper here suggests that more attention needs to be paid to the provenance of both individual objects and of whole collections, in order to assess the potential of their information and interpretation.

Focusing on the "traditional costume" collections existing in Greece today, I will attempt to describe how these were created and why they are important both as a historical source and in respect of identity issues. I will then attempt to draft a roadmap for the work that could be done when searching for their provenance and conclude with how this could lead to a reconsideration of established perceptions about 'traditional' dress.

\section{Collections of Traditional Costumes in Greece: Origins and Development}

In Greece there are many collections of the so-called "traditional" or "local" costumes, i.e., specimens of dress used in Greek areas from the 18th century onwards [6]. The political, social and economic circumstances of the time favored a community-structured system of administration and living; spending all their lives within the boundaries of their community, its members came to be strongly defined by this community, and identified with it in every way, their dress habits included. This resulted into the development of different dress types, each one typical of a particular community and its geographical location and easily recognizable as such. Simple and plain in their everyday form, the same types of garments were more decorated and impressive in their wedding and festive versions. They often bore elements indicating the age, and the marital and social status of the wearer, thus serving as a social code inside the community. As a result, both daily and festive outfits were standard and 
specific sets of garments, which were made in standard and specific forms, and worn in a standard and specific order. Variation was limited to the decorative motifs (as a consequence of taste, dexterity, creativity and so on) and the quality of textiles and making (according to a person's or family's capabilities, priorities etc.). Conformity to such dress standards resulted in a quite apparent uniformity in people's appearance within each community. Because of these characteristics the word "costume" is often used when referring to this kind of dress. For as long as the change of the communities was slow, the change in their dress was slow, too. But in the course of the 19th century, radical changes in all aspects disrupted the structure and nullified the substance of the local communities, eventually wiping out the old lifestyle and the costumes related to it.

Not all "traditional" outfits were abandoned at the same time. This was a process that began in the early 19th century, culminated in the turn from the 19th to the 20th century and concluded with World War II. During this period of over 100 years, while their actual users discarded them as out-of-date, inconvenient and inappropriate for their changed—or aspiring to be changed-lifestyle, the intellectual and social elite, both home and abroad, developed a gradually increasing interest in them.

Collecting exotic curiosities and exhibiting them as prestigious home decorations, had been wide-spread in the Victorian and Edwardian Britain and other European countries [7] (pp. 29-64). Furthermore, by the last quarter of the 19th century, admiration for the "pure" folk culture of rural communities that had remained "unspoiled" by the industrialized and urbanized Western life, led scholars, artists, aristocrats and wealthy bourgeois all over Europe to an enthusiastic search and preservation of their clothes, textiles, utensils, etc. [8]. Alongside this, the Arts and Crafts movement was quickly gaining ground, generating, among other things, a wish to provide training, inspiration and opportunity for employment in craftwork. All the above shaped the intellectual and social milieu in which British archaeologists and diplomats positioned in Greek areas (such as Theodore Bent, R.M. Dawkins, A.J.B. Wace and Thomas Backhouse Sandwith) started to notice, collect, publish and exhibit elaborate Greek embroideries, including garments ([9,10]; [11] p. 263; [12]). Affected by the same milieu, but also in an effort to build up a national image based on the perception of Greek culture as a continuum from the antiquity to the present, Greek State authorities, institutions and individuals also began collecting and exhibiting folk handicrafts. The abandoned garments were treated as art works, heirlooms worthy of safeguarding, decorative items, commodities with trade value, and models for contemporary craft production. Collections were created, books were published, museums and craft schools were founded, dance groups were set up, and folk handicrafts featured as urban domestic decoration.

Having its origins in late 19th and early 20th century, this trend came to dominate intellectual and artistic life in the 1920s and 1930s, the crucial-for the development of modern Greek mentality and identity - period between the two World Wars. From the 1950s to the 1970s, after the catalytic effect WWII and the subsequent Civil War had on people's lives in villages and towns, and in the framework of the sweeping urbanization, a salvation agony further fuelled the collective motivation of all already involved in the trend: to rescue for eternity whatever was left of the 'extinct' folk culture. Itinerant sellers rummaged the country and sold items to museums and private collectors by the lot. A typical example, the Museum of Modern Greek Culture holds hundreds of almost identical aprons, chemises, and socks purchased in that period and in the name of safeguarding as well as creating complete series for classification and study purposes.

An interest in collecting; an idealized perception of the "folk" and an urge to protect them from industrialization and urbanization; the Arts and Crafts movement; and, in the case of Greece-and other Balkan and European countries as well ([13] pp. 201-228; [8])—a need to prove continuity from the past and build national identity and the State; these were, more or less, the motivations that instigated and sustained costume collections in Greece from the late 19th century onwards. 
Collectors, researchers, genre artists, museum founders, directors and curators, patrons of craft schools and other institutions: the persons who shared the above motivations also shared a similar social, economic and ideological profile. They were usually bourgeois, well-read and well-off people, in other words the social, intellectual and artistic elite of their time. Actually, most of them had no "organic" association with the life-structure and life-style of the "folk" and regarded them, more or less, as exotic.

Some objects were collected in situ, purchased directly from their owners' trunks in villages and small towns. But far more were the ones bought from antique-sellers and peddlers. Although important, their intermediation in the collecting process has not yet been adequately acknowledged and studied [14]. They were the ones in immediate and frequent contact with the actual users, and the actual places of use, of the objects. The information they gave on the geographical origin and the general function of a garment was often the only documentation recorded. The practice of combining different clothes in order to put together costumes that were seemingly complete or just more appealing to the buyer was not unusual. Their intervention in mending or "improving" the often worn-out clothes cannot be ruled out either. Their clients' tastes and demands both guided their choices and were guided by them. All these factors form a perplexed grid of ties and links. Sellers' profiles, their criteria of choice, their level of knowledge, their perception of professional ethics, and their relationship with the collectors, have considerably affected the objects collected and what is known about them.

The motivations and the profile of both collectors and their providers have largely defined the content of the collections: the kind of items and information collected, and the way they were interpreted and presented. To a great extent they also account for the kind of items and information that have been left out.

The collecting process roughly sketched above valuated garments as admirable handicrafts, continuity proofs and identity symbols. Classifying each collected item under a certain dress type and referring it to a certain geographical and cultural terroir was enough for its documentation. Techniques and decorative motifs also enjoyed attention, in an aesthetic and artistic point of view or to the end of revealing intrinsic ties with antiquity. Up to the 1990s, investigating the particular details of the history of an object-its biography-was not in the scope of scholarly research and museum recording (unless it could be linked to a well-known person or family). Evidence on individual makers' and users' biographies; on places, times and circumstances of making and use; on the course from use to disuse and then to the museum, was not recorded.

The same reasons explain why the pursuit, at a museum, research and political level, was for the beautiful, the impressive and the "appropriate". Undecorated, humble, worn-out garments did not have a place in the collection practice [5] (p. 47); neither did the garments identified with cultural and/or ethnic groups that were excluded from the mainstream national narrative.

\section{The Use of "Traditional Costumes" Today}

Meanwhile, since the 1830s and the foundation of the Greek State, local costumes in their most glamorous and luxurious versions were turned into national costumes and military uniforms. To this day they have been used as a basic element of the national image by the major national institutions: the State, the army, the school. It is worthy of notice how the narrow limits of the specific locality characterizing these costumes in the first place have been stretched to coincide with the much broader boundaries of the national State, whose very establishment was a victory over the defining locality of the community-structure system. 
Since the 1910s folk-dance groups were set up, who were teaching, and publicly performed, local dances. While many of these groups initially collected and used original costumes in their performances, later on they put aside the original ones and used replicas instead.

Nowadays "traditional costumes" can be seen worn quite often: by the Evzones Guard at the Tomb of the Unknown Soldier in front of the Greek Parliament; by ceremonial groups receiving foreign officials; by schoolchildren in parades honoring national anniversaries; in dance performances at public spaces (Figure 2), on television shows; and so on. The costumes actually used in most of these instances are replicas, often made of lighter and cheaper materials than the originals. They are usually identical for all members of a group, and people have come to call them "uniforms" ( $\sigma \tau \sigma \lambda \dot{\varepsilon} \zeta$ ) more often than "costumes" ( accuracy and authenticity in form and appearance. As this is perceived to be a matter of national identity and pride, trust in historical validity and claims of authenticity are important.

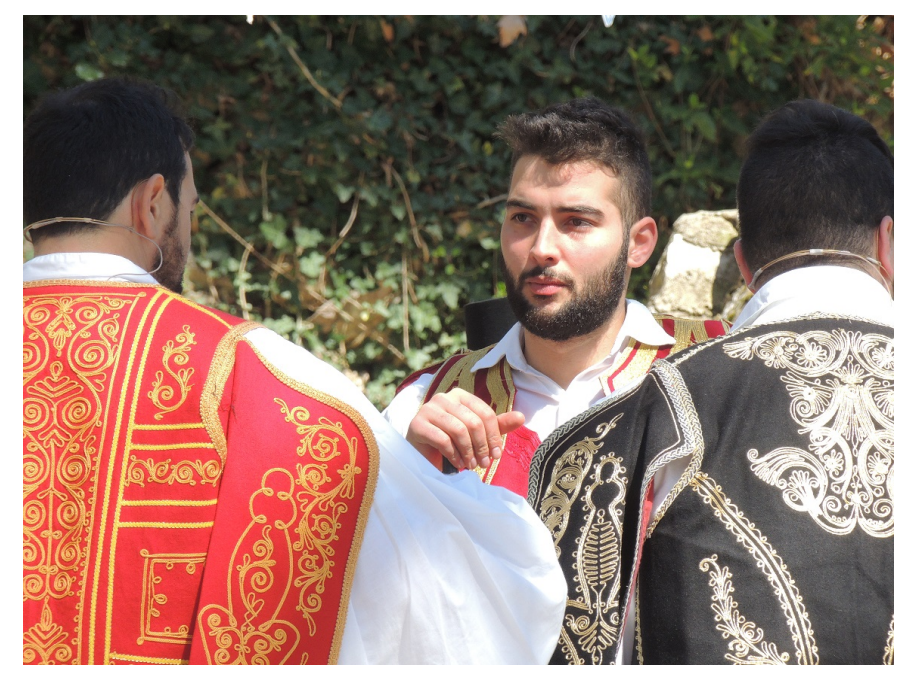

Figure 2. Theater and dance performance for the national anniversary of 25 March 2014.

\section{In Search of Provenance: Putting Together Biographies of Collections and Objects}

"Traditional costumes" collections are valuable a) because of the significance this kind of wear had, and still has, for national image, narrative and aspirations, for the collective and individual identity; and b) because the extant clothes (dated roughly from the 18th to the mid-20th century) and the collections of them can be useful historical sources which, I think, have not yet been fully exploited and meaningfully related to other available sources (archival, visual, oral etc.) of the same time for the study of various historical issues besides folk culture or dress history.

An important parameter affecting the kind and validity of the information that may be provided by a historical costume in a collection, museum or other, is its provenance: how it was acquired and what is known about its "life" before. The same stands, proportionally, for a historical costumes collection as a whole: its potential as a source for the understanding of material culture and as a field for different interpretations is largely dependent on its provenance: the way it has been created.

Since the provenance of both individual objects and collections as entities deeply affects our knowledge of them and their interpretational potential, it is critical to ask questions such as the following [15] (pp. 115-117): With what criteria and intentions were these clothes collected? What was preserved and what was left out? Which routes did the objects follow on their way to collections, who and what came in their way? To what extent was their form affected, altered or distorted? How much and what kind of information were they "allowed" to carry along? How sure can we be of their "authenticity"? Also, what really is the measure by which to judge "authenticity"? 
To an extent, the provenance of a collection-its history-is constituted by the individual histories of both the objects which comprise it and the subjects who contributed in its creation and development:

1. Collectors, private or institutional

2. "Administrators": museum directors and curators, conservators, exhibition planners; collectors' descendants, heirs and successors; managers, dressers and members of dance groups

3. "Providers": antique-sellers, "traditional" costume makers, users and their descendants, systematic and circumstantial collectors

4. Researchers, scholars, academic teachers, artists etc.

Surely the history of a collection is not just the sum or even the product of the histories of the persons involved in it; but their biographies will definitely illuminate its provenance [16,17].

Furthermore, the composition of a collection's own biography can borrow elements from the methodology applied when putting together a person's biography. A detailed questionnaire should cover the circumstances of the collection's birth and growth, the stages and landmarks of its "life", persons associated with it, facts that affected it, places where it "lived", time periods of its "life" and so on. Since a collection is not a person to be interviewed, answers will have to be sought from a variety of sources:

1. The life, work and material left from persons associated with it in the past

2. Interviews with persons associated with it in the present In both cases, persons from all categories defined above (i.e., collectors, curators, sellers, researchers etc.) should be investigated, with an emphasis on revealing their particular motivations and attitudes in the collection and interpretation processes, as well as their background, mentality and overall profile.

3. Records and archives of any kind: museum registries, inventories and catalogues, fiches, documents, invoices, collectors' lists and notes etc.

4. Articles and books, exhibition catalogues, publications, magazines and scholarly journals

5. Photographs of: objects, storage, exhibition premises; or, in the case of dance groups' wardrobes, of performances, parades etc.

6. Last but not least, the objects themselves: search for signs, stamps, signatures, hand-written names, labels, any material marks of their origin and different contexts of their use; study their morphology (indicative of the place of making, the techniques and materials used, their makers' and users' technical, economic, social, and aesthetic profile); spot alterations and mends, different stitches and threads; etc.

The collection should then be compared with, and related to other collections of the same type, in order to spot similarities, differences, and relevancies. Finally, the resulted information should be placed in a wider setting, and linked to the social, political, economic, ideological etc. context and historical events. The above may apply when investigating the provenance either of a whole collection or a single object.

Nowadays, at the Museum of Modern Greek Culture we meticulously gather all kinds of information when acquiring a clothing item: oral testimonies (interviewing the owner/s and user/s), documents, photographs etc. $[18,19]$. However, for the majority of the clothes in our collection, acquired from its establishment in 1918 until the 1990s when research interests changed, there is no information on the particular details of their making and use. The same stands for all the existing dress collections. The exhaustive search outlined above aims not only at retrieving more information on the use context(s) of an object, but also at better understanding its collection context(s), i.e., a) the context of the very act of it being collected and b) the overall collection in which an object is included. In other words, we should extend our search from the historical circumstances of an object's manufacture and use to the historical circumstances of its "discovery", "rescue" and "acquisition" [20]. 
Its transformation into a collection-worthy item and its life thereafter is, from a historic point of view, an equally "responsive" - although to different questions—stage in its life.

Many of the objects existing today in public and private collections in Greece were provided by the same people: antique-dealers and peddlers, researchers, and big and small collectors. Knowledge on the life and deeds of each one of these providers would shed, if not a stronger, surely a different light on the objects that passed from their hands. All interested parties, starting with museums, could share information and create a repository, where gradually each provider's profile will be sketched, links and courses will be trailed, connections and relations between people, objects and ideas will be revealed [21]. ICTs provide abundant means for the realization of such a project.

\section{In Conclusion: Redefining our Perception of "Traditional Costumes"}

Provenance of knowledge on historical dress is a long and uncertain path running through knowledge of provenance of the extant items, i.e., through antique-dealers, peddlers, collectors, museum directors \& curators, artists, researchers, craft patrons and so on.

Collection is generally regarded as an act of rescue, safeguarding and preservation. However, at the same time it is an act of loss, damage and extinction. Every time an item is "collected", it is removed from a given context, and a certain amount of information is irrevocably lost; a number of potential perspectives for its interpretation are ruled out. Likewise, every time an item is "collected", many others are not, as a result of either selection procedures or chance. More often than not, this one item is laden with the burden of "representing" a whole category, not necessarily because it has been verified to have the typical features of the category, but just because it happens to be the "one" extant sample of it. That is why the biography of a collection should try to spot and explain its shortcomings (in all aspects: collecting, recording, documenting, managing, presenting and so on) as well as its assets. When approaching a collection, we should also listen to its "silences", since what it doesn't "say" is equally interesting with what it "says".

The way and the reasons that a specific type of clothes was collected in Greece from the late 19th until the late 20th century has led to a specific perception of this kind of wear as "costumes" of local origin but national significance, characterized as precious, picturesque, beautiful, symbolic, conservative, collective, and so on. Even the verbal treatment of the existing collections testifies that their purpose so far has been to function as arcs of certified "authentic" and "complete" sets of clothing: they are called collections of "costumes" ( $v \delta v \mu \alpha \alpha \sigma \varepsilon \zeta)$ and "costume parts" or "accessories" $\left(\varepsilon \xi \alpha \rho \tau \eta_{\mu \alpha \tau \alpha}\right)$; an individual item, such as a chemise or a coat, is no more than a "part", i.e., it cannot stand on its own. Gathering as much information as possible from any probable source will help transform "costumes collections" to "dress collections", since the quest today is shifting from treasuring typical outfits of a totem-like static quality and a national sacredness to understanding dress habits and forms as a particular area of both material and immaterial culture, inextricably related to all other aspects of life and culture.

Furthermore, after acknowledging the "filters" involved in the collection and study processes of "traditional" dress all axioms about it should be challenged and re-examined. To aspire to remove the "filters" of the past is hopeless. The effort should be in bringing these filters into the focus and re-thinking what we think we know, still knowing in the back of our minds that some new-or not so new-filters (of our time, place, personality etc.) are bound to be applied.

Funding: This research received no external funding.

Conflicts of Interest: The author declares no conflict of interest. 


\section{References and Notes}

1. The discussion raised in this paper is part of the ongoing work for my $\mathrm{PhD}$ thesis: "Dress collections in Greece (late 19th-early 21st century): Museums, collectors and antique-sellers in a process of collecting, rescuing and studying". 2nd year of preparation, University of Ioannina, Greece (supervisor: Professor Marina Vrelli-Zachou).

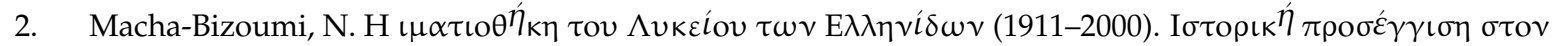

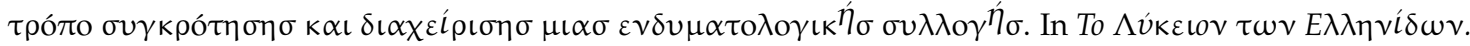
$100 \chi \rho \delta ́ v \iota \alpha$; [The wardrobe of the Lyceum Club of Greek Women (1911-2000). A historical approach to the constitution and management of a dress collection. In The Lyceum Club of Greek Women. 100 Years]; Avdela, E., Ed.; Piraeus Bank Group Cultural Foundation: Athens, Greece, 2010; pp. 193-231.

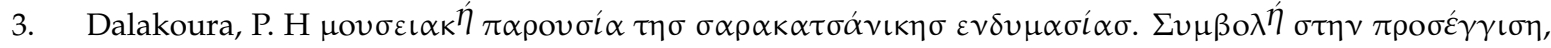

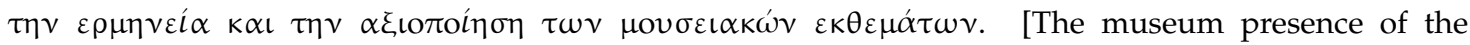
Sarakatsani dress. A contribution to the treatment, interpretation and valorization of museum exhibits]. Ph.D. Thesis, University of Ioannina, Ioannina, Greece, 2016.

4. Politou, X. Dress Collections in Greece. An Attempt to Survey the Existing Dress Collection Landscape with a View to Establishing a Costume Culture Museum in Greece. In Proceedings of the Endyesthai (To Dress). Historical, sociological and methodological approaches, Athens, Greece, 9-11 April 2010.

5. This essay was first presented in 2011 at the 6th Symposium of Studies on Thassos, and published as an

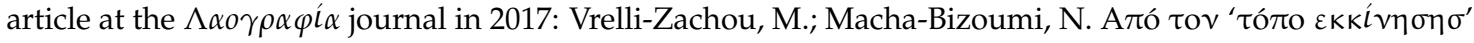

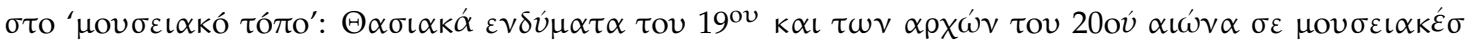

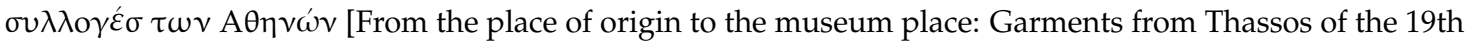
and the early 20th century in Athens museum collections]. $\Lambda \alpha 0 \gamma \rho \alpha \varphi i \alpha 2017,43,45-69$.

6. For an introduction to Greek dress history including 'traditional' wear, see Papantoniou, I. In Greek Dress. From Ancient Times to the 20th Century; Commercial Bank of Greece: Athens, Greece, 2000.

7. Belk, R.W. Collecting in a Consumer Society; Routledge: London, UK; New York, NY, USA, 1995.

8. Crawley, D.; Taylor, L. (Eds.) The Lost Arts of Europe. The Haslemere Museum collection of European Peasant Art; Haslemere Educational Museum: Haslemere, UK, 2000.

9. Bent, T. The Cyclades or Life Among the Insular Greeks; Longmans, Green, and Co.: London, UK, 1885.

10. Dawkins, R.M.; Wace, A.J. Catalogue of a Collection of Old Embroideries of the Greek Islands and Turkey; Burlington Fine Arts Club: London, UK, 1914.

11. Taylor, L. Establishing Dress History; Manchester University Press: Manchester, UK, 2004.

12. French, A. The Greek embroidery collecting of R.M. Dawkins and A.J.B. Wace. British School at Athens Studies 2009, 17, 77-90. Available online: http:/ / www.jstor.org/stable/40960674 (accessed on 12 January 2019).

13. Taylor, L. The Study of Dress History; Manchester University Press: Manchester, UK, 2002.

14. Such work for the British case has been done by Mark Westgarth in his PhD thesis: The Emergence of the Antique E Curiosity Dealer 1815-c.1850: The Commodification of Historical Objects. University of Southampton, Southampton, UK, 2006. In it he investigates the antique and curiosity dealers' role in early 19th century Britain. See also [20].

15. Pearce, S.M. Museums, Objects and Collections; Leicester University Press: Leicester/London, UK, 1992.

16. Larson, F. An Infinity of Things. How Sir Henry Wellcome Collected the World; Oxford University Press: Oxford, UK, 2009.

17. Delbourgo, J. Collecting the World. The Life and Curiosity of Hans Sloane; Allen Lane: London, UK, 2017.

18. Papathoma, E. From the Mountains to the City Streets. Multiple Approaches to a Child's Parade Uniform. In Proceedings of the 2014 Annual Meeting of the ICOM Costume Committee, Nafplion and Athens, Greece, 7-13 September 2014.

19. Papathoma, E. An 'Ethnic' Souvenir for a WWI Nurse. Available online: http://www.clothestellstories.com/ index.php/component/content/article/10-telling-stories-with-clothes/63-an-ethnic-souvenir-for-a-wwinurse (accessed on 12 January 2019).

20. Jones, J.P. The Colonial Legacy and the Community: The Gallery 33 Project. In Museums and Communities: The Politics of Public Culture; Karp, I., Kreamer, C.M., Lavine, S.D., Eds.; Smithsonian Institution Press: Washington, DC, USA, 1992; pp. 221-241. 
21. Cf. the Centre for the Study of the Art and Antiques Market of the University of Leeds [available online: http:/ / csaam.leeds.ac.uk (accessed on 12 January 2019)] and the 'Antique Dealers' project based at the same University and led by Dr Marc Westgarth [available online: http:/ /www.antiquedealers.leeds.ac.uk (accessed on 12 January 2019)]. 